\title{
The Relationship Between Population Growth and Economic Growth in Ethiopia
}

\author{
Kidane Alemu \\ Lecturer \& Head of Department of Economics ,Dambi Dollo Universiy,Ethiopia
}

\begin{abstract}
This paper examines the relationship between population growth and economic growth in Ethiopia using time series data from 1980/81-2018/19 and in a multivariate framework. Results from Philips Person unit root tests show that the time series under consideration contain I(1) variables implying that the model adopted(that is, ARDL methodology) is quite appropriate. Result from ARDL Bounds testing indicates that there exists long run relationship (co-integration) among the Ethiopian population growth and economic growth when real Gross Domestic Product (RGDP) is taken as dependent variable. The coefficient of the estimated error correction term is found to be -0.921244 and it is highly significant, further confirming the existence of long run relationship. It means that it takes only one year and about a month for the short run disequilibrium to adjust towards the long run equilibrium. The empirical model reveals that population growth has highly significant positive relationship with economic growth of Ethiopia both in the short-run and long run. Moreover, Toda-Yamamoto and DoladoLutkepohi as well as Innovative Accounting Techniques (that is, IRFs and FEVD) approach to Granger causality analysis show that there exists bidirectional causality between population growth and economic growth and also both are witnessed to be strong as of impulse response and variance decomposition results. The implications of the findings are that population is an asset rather than a burden for Ethiopia, and therefore a carefully planned population expansion along with well stable macro-economy, better employment opportunities and expanded quality education given equality and justice in social, political and economic spheres would drive the economic growth and development in the country.
\end{abstract}

Keywords: ARDL, Economic growth, Ethiopia, Population Growth

DOI: $10.7176 / \mathrm{JESD} / 11-15-07$

Publication date:August $31^{\text {st }} 2020$

\section{Introduction}

Population growth can have several effects on the economic expansion and performance of a country. On the other hand, Population growth and economic growth are highly interrelated since they affect each other. Their relation has attracted the attention of economists since economics was established as self-discipline. For instance, Adam smith, the so called the father of economics, wrote that "the annual labor of every nation is the fund which originally supplies it with all necessaries and conveniences of life', (Jhagan, 2002)

When people started to cultivate the land to produce food through agriculture some 1200 years ago, the estimated world population was not more than 5 million. From year 1 on our calendar to the begging of the industrial revolution around 1750, world population tripled to 728 million people which are less than three quarter of total number living in India today. During the years 1750-1950, 1.7 billion additional people were added to the planet's population number. But after four decades, the earth's human population doubled again, bringing the total figure to around 5.3 billion. The world welcomed the twenty first century with over 6 billion people .And assuming that it will continue to grow with such trends, it is projected that the total world population to be reaching to 9.7 billion in 2050 and 11 billion 2200(Todaro,2003).

Although the world has witnessed unprecedented population growth during the last 50 to 60 years, faster growth than any other 50- to 60-year period, the rate of growth has been decelerating since its peak rate of 2.3 percent yearly in 1960 to 1.3 percent in 2005 to an expected 0.8 percent in 2025 and 0.4 percent in 2050 . This shows reduction in the growth rate of population resulted from factors such as: urbanization, greater economic aspirations, increased female education and labor force participation, and more accessibility to family planning (Marthin, 2009) .The current world population is 7.5 billion with the growth rate of $1.14 \%$ per year. From this total, about eighty-one percent live in Less Developed Countries.

Africa has the fastest growing population in the world. Currently, the total population of Africa is about 1.2 billion people, which will double it after 29 years and it is being estimated at about 2.4 billion in 2050 . Consequently, this might hinder the achievement of planned family which is very significant to moderate population growth in the continent (CIA WFB, 2014).

Ethiopia is the second most populous country in Africa next to Nigeria. The total population was about 39.1 million, 53.1 million, 73.9 million and 94.1 million according to the first census (1984), the second census (1994), the third census (2007) of the population and the 2012 Inter Censual Population Survey (ICPS), respectively (CSA, 2007). The current total population of Ethiopia is estimated at 102.4 million with the growth rate of $2.38 \%$ and 29 years of doubling time. 
Obviously, it is witnessed that the world, the continental and the national population is increasing with changing economic system despite the projected decreases in its growth rates. However, there is no agreement on the impact of such a growing population on economic growth. As a result, the debate on the relationship between population growth and economic growth has been undergoing and it varies across countries. The first theory view population growth as a factor that adversely affects economic growth. The second theory states that population growth stimulates economic growth. While the views of a third school is that population growth is a neutral factor in economic growth and is determined outside the standard growth models (Obere et al., 2013)

Nevertheless, matching population growth with development is the real object of global and national action towards improved welfare, human development and economic growth. The changing patterns in the size, structure and distribution of population provide useful leads into the persistent shifts in the choice of approaches for managing development (Rostow, 1998).

Hence, it is the great interest of the researcher to formulate an empirical framework to determine the relationship between the growing population and economic growth in Ethiopia.

\subsection{Objective of the Study}

$\checkmark$ The main objective of this research work is to empirically examine the relationship between population growth and economic growth in Ethiopia during the periods 1980/81-2018/19.

\subsection{Working Hypotheses}

The study is based on the following null hypotheses:

i. There is no significant long-run relationship between population growth and economic growth in Ethiopia.

ii. Economic growth does not Granger-cause population growth and Population growth does not Granger cause economic Growth in Ethiopia.

\section{Review of Related Literatures}

The total population of any area of the earth's surface represents a balance between two forces. One is natural change caused by the difference between the number of births and deaths. If births are more numerous than deaths in any period, the total population will increase. However, if they are less numerous it will decrease. This simple relationship is modified by a second force; migration. When immigrants are more numerous than emigrants, there will be a population increase (We assume, of course, that we are ignoring natural change for the moment). When emigrants are more numerous, there will be a population decline (Ben, 2005) as cited in( Nwosu et al.,2014).Net changes in population totals are caused by the interaction of four elements: Births and immigrants tend to push the total up: Deaths and emigrants tend to bring the total down. Although migration may be the most important factor in small areas (for example, in a small village or a city block), it is less significant on the national level.

Theoretically, the impact of population growth on economic growth has always been a subject of disagreement among economists, that is, they are torn between three theories; one that state's that population growth helps a nation's economy by stimulating economic growth and development (for example see, Simon, 1977) which is based on argument of Boserup(1965) and another that bases its theory on Robert Malthus' findings. Malthus (1798) stated that population increase is detrimental to a nation's economy due to a variety of problems caused by the growth. For example, overpopulation and population growth places a tremendous amount of pressure on resources, which result in a chain reaction of problems as the nation grows. The third school of thought (the neutralist view of population) argues that population growth does have no impact on economic growth.

In empirical regard, Gideon et al. (2013) conducted a study to determine the impact of population change on the economic Growth of Kenya by employing Vector Auto Regression (VAR) estimation technique and using annual time series data. Their results indicated that population growth and economic growths are both positively correlated and that an increase in population will impact positively to the economic growth in the country. Thus, they conclude that in Kenya population growth promotes economic growth and subsequently economic development as suggested by the optimistic theory of population.

Nwosu et al.(2014) investigated the time series role of population growth on economic growth in Nigeria and how economic growth is effected through population growth. They extended the literature by employing a VAR Model to analyze economic growth fluctuations visa-vise population growth and it was based on Augmented Dickey-Fuller (ADF) stationarity test combined with Granger Causality and Co- integration tests.The empirical results of this study also supported that population growth has a significant positive impact on economic growth. It also found that there is a sustainable long run equilibrium relationship between economic growth and population growth. And there is also the evidence of unidirectional causality between population growth and economic growth

In contrast, Emmanuel (unpublished) empirically tested the association between population growth and economic development by using the Blancher's model in Nigeria between 1980 and 2003 found that growth in population outweighs that of output and this has hindered the capacity of successive governments to efficiently 
provide social services to the people, there by negatively affecting development.

Although it was not recently, Bloom \& Freeman (1999) conducted a research on demographic changes and economic growth in Asia using cross-country regression equations. The authors tried to account for the effects of demographic variables on growth by introducing a number of demographic variables such as growth rates of total population and working age population, the population of the initial working age population to total population, life expectancy, and population density.

Their study revealed that variables such as the growth of working age population and life expectancy have a positive effect on growth while total population and population density have negative effect on economic growth, impacts of total population giving statistically insignificant. Thus the authors conclude that though the overall rate of population growth had little effect on economic growth, most of the "East Asia's economic miracle" is explained by demographic transition.

On the other hand, Todaro \& Smith(2003), on his part conducted a research on this area. And he identified seven negative consequences of rapid population growth on economic development. These are the consequences (costs) of rapid population growth on: economic growth, poverty and inequality, education, health, food, the environment and international migration.

Kassahun(2014) conducted study on the impact of population on the economic performance of Ethiopia. He used a neo-classical growth model fit with the Error Correction Model based on Ordinary List Square (OLS) estimation techniques of the time series with some modification of population exogenous assumptions and concluded that population issue related to economic growth is very controversial because it has negative impact in the short run but positive impact on economic growth in the long run.

According to this study, the implication of the short run negative result and the positive result in the long run explains that large number of economically dormant people with high growth rate of population depresses the country's economic growth. Nevertheless, the economy can adjust in the long run and absorb existing people as labor force and that the influence of population can be avoided, so those, the people can play as an active actor of economic development of the country.

\section{Methodology}

The design of the study is hypothesis -testing research design. And the study used annual time series data comprising observations over the period of 1980/81- 2018/19. The data were obtained from Ministry of Finance and Economic Development (MoFED) and Central Statistical Authority of Ethiopia (CSA).However, in order to avoid data inconsistency problem; attempt has been made to stick on the same source, that is, the data obtained from Ministry of Finance and Economic Development (MoFED) are mainly relied in the study. And the standard econometric estimation techniques were used to examine the regression between population growth and economic growth and to test the TDYL causality. Data analysis was facilitated through the use of Eviews 10 and Stata14 packages.

\subsection{Conceptual Framework and Model Specification}

The empirical model adopted to examine the long run and short run relationship between population growth and economic growth is an Autoregressive Distributed Lag (ARDL) model (Bound testing methodology) proposed by Pesaran and Shin (1997 \& 1999) and Pesaran et al. (2001).

The theoretical foundation of the study is based on neoclassical growth model. Kassahun (2014), Nwosu et al. (2014) and Gideon et al. (2013) have also adopted their econometric models from similar growth model in their attempt to examine the relationship between population growth and economic growth. Thus, the following economic growth function can be specified:

$R G D P g r o w t h=f($ populationgrwth $(n)$, Labor force growth $)$

The population variable is transformed into natural $\log$ in order to remove or reduce considerably any Heteroscedasticity in the residuals of the estimated model following (Gujarati, 2004).The log-log form specification also enables the researcher to interpret the coefficient of the dependent variable directly as elasticity with respect to the independent variables as of Sarmad(1988) as cited in (Nesredin,2015). Therefore, the econometric model of equation (3.1) with the natural log is given below:

$\ln R G D P t=\beta o+\beta 1 \ln P O P t+\beta 2 P D+\varepsilon t$.

Where RGDPt is the real GDP at time t,POPt is the total number of Ethiopian population at time t,PD is dummy variable for policy changes which takes zero for the period 1980/81 to 1990/91 and one otherwise. $\beta_{0}$ is the intercept term of the model which depicts the level of economic growth that would exist with zero levels of the repressors. $\beta 1$ measures the partial elasticity's of real GDP growth with respect to population growth and $\beta 2$ is the coefficient of the dummy variable in the model. et is stochastic variable at time $t$ which accommodates the influence of all other determinants of economic growth not included in the model, and ln is natural $\log$. 


\subsection{Econometric Estimation Techniques and Procedures}

\subsubsection{Unit Root Test}

A stochastic process is said to be stationary if its mean and variance are constant over time and the value of the covariance between the two time series depends only on the distance or lag between the two time periods ,but not the actual time at which the covariance is computed. In other words, there exists stationary process if it generates constant mean and variance. Conversely, if the time series is not stationary, it is called non-stationary time series which have a time varying mean or a time varying variance or both. In this case it is impossible to use simple Ordinary List Square (OLS) to estimate the long-run linear relationships between variables. If we do so, it would lead to spurious regression (non-sense economic analysis) where R-squared is very high (that is,in excess of 0.9), $\mathrm{t}$ and F-statistics look significant and valid but not in fact (Gujirati,2004; Vebrek ,2004)

If the presence of spurious regression is not detected, one will be obliged to falsely concluding that there is a relationship even though there is no meaningful relationship between the non-stationary time series variables (Anonymus,2011).As a way to solve this problem, Granger (1969) suggested that a coefficient of determination greater than the Durbin-Watson statistics $(\mathrm{R} 2>\mathrm{d})$ is a good rule of thumb to suspect that the estimated regression is spurious. Once detected, a unit root problem can be solved by differencing the data set as to ( Gujirati ,2004).

If the variable is stationary without differencing, then it is integrated of order zero, $\mathrm{I}(0)$. And a variable is said to be integrated of order one, or I(1), if it is stationary after differencing once, or of order two, I(2), if differenced twice.

Although applying ARDL methodology does not require pre-testing for order of integration, unit root test is conducted in this study so as to ride out from the problem of spurious regression and so as to check that none of the series is I(2) since the application of ARDL model is not justified with such order.

Augmented Dickey-Fuller (ADF) test, Phillips Perron (PP) tests and Kwiatkowski- Phillips-Schmidt-Shin (KPSS) tests are the common tests for unit root. However, in this study, the Philip Perron (PP) test is used since it has greater power than the Augmented Dickey-Fuller (ADF) test.

The Dickey-Fuller test involves fitting the regression model:

$\Delta X t=\rho x t-1+($ cons $\tan t$, time trend $)+\varepsilon t$

$\Delta x t=\alpha+\beta t+\phi x t-1+\sum \gamma i \Delta x t-i . .+\varepsilon t$.

Where $\mathrm{i}=2,3,4 \ldots \mathrm{n}$. (3.4) called augmented Dickey-Fuller $(A D F)$ test. It accounts for the serial correlation problem that presents in (3.3) by including lags of the first differences of xt. The Phillips- Perron test involves fitting (3.5) as below, and the results are used to calculate the test statistics:

$x t=\omega x t-1+($ cons $\tan t$, time trend $)+\varepsilon t$

In (3.3) \&t is assumed to be I(0) and may be heteroskedastic but (3.5), the PP test corrects for any serial correlation and Heterokedasticity in the errors ( $\mathrm{ct}$ ) non-parametrically by modifying the Dickey Fuller test statistics.

Phillips and Perron's test statistics can be viewed as Dickey-Fuller statistics that have been made robust to serial correlation by using the Newey-West(1987) Heterokedasticity and auto-correlation-consistent covariance matrix estimator.

Under the null hypothesis that $\rho=0$, the PP Zt and Z $\pi$ statistics have the same asymptotic distributions as the ADF t-statistic and normalized bias statistics. And the advantages of the PP tests over the ADF tests are:(1) the PP tests are robust to general forms of Heterokedasticity in the error term (2) the user does not have to specify a lag length for the test regression.

3.2.2 Co-integration Test: ARDL (Bounds) Testing Approach

Co-integration means that despite being individually non-stationary, a linear combination of two or more time series can be stationary (Gujarati,2004).Said in another words, if a group of time series variables are individually integrated of the same order and if at least one linear combination of these variables is stationary, then the variables are said to be co-integrated and it indicates that there could be a long run equilibrium relationship between these time series variables (Harris, 1999 \& Enders, 2004).But, if two or more time series variables are not co-integrated, surely there is no long run relationship between them.

Testing for the existence of such a long-run relationship between economic variables is called testing for cointegration. And a number of methods for testing co-integration have been proposed in the economic literature. The most common are the Engle-Granger procedure, the Johansen's co-integration procedure and Autoregressive Distributed Lag (ARDL) method of co-integration .However; this study used the ARDL approach of Testing Cointegration for its advantages over the other two approaches.

To overcome the limitations of the other two convectional approaches, Pesaran and Shin (1999) and Pesaran et al.(2001) proposed the Autoregressive Distributed Lag (ARDL) /Bound Testing methodology. This has been the most recent and the most popular in econometric literatures.The features and advantages of ARDL methodology are: 
i. It can be applied irrespective of the order of integration as long as $d_{\max }$ is less than two. That is, the ARDL methodology is applicable no matter even if there is mixed order of I (0) and I(1) variables within the series.

ii. It provides statistically significant result in small samples unlike the Johansen co-integration techniques which require large data samples for validity.

iii. It gives unbiased and valid estimates of the long run model even when some of the repressors are endogenous.

iv. It involves just a single-equation set-up which makes it simple to implement and interpret.

v. Different variables can be assigned different lag-lengths as they enter the model.

vi. A dummy variable can be included in the co-integration test process, which is not permitted in Johansen's method (Rahimi \& Shahabadi, 2011) as quoted in (Dawit,2013).

Thus, the following ARDL model can be specified in order to test the long-run relationships (co-integration) between variables following ( Pesaran \& Shin, 1997 \& 1999) and Pesaran et al. (2001):

$$
\Delta \ln R G D P t=(\alpha 0, \text { trend })+\sum_{i=1}^{p} \alpha 1 \Delta \ln R G D P t-i+\sum_{i=1}^{p} \alpha 2 \Delta \ln P O P t-i+\theta 0 \ln R G D P t-1+
$$

$\theta 1 \ln P O P t-1+\theta 3 D+\varepsilon t$

Where the variables are as defined previously and $\theta 0, \theta 1, \theta 2 \& \theta 3$ are long run coefficients that measure long run relationships, $\alpha 0$ is the intercept ,and $\alpha 1$ and $\alpha 2$ are short run coefficients that measure the short run relationships, $\varepsilon t$ is an error term and $p$ denotes the optimal lag length of the auto regressive process, $\Delta$ is difference operator and trend is the time trend of the model.

From equation (3.6), we first test the null hypothesis of no co-integration, that is, $\mathbf{H 0}: \Theta 0=\boldsymbol{\theta 1}=\boldsymbol{\theta 2}=\boldsymbol{\theta 3}=\mathbf{0}$ against the alternative one, which is, $\mathbf{H 1}: \Theta 0 \neq \mathbf{\Theta 1} \neq \mathbf{\Theta 2} \neq \mathbf{\Theta 3} \neq \mathbf{0}$ using the F-test with upper and lower critical values that are calculated automatically and reported after the ARDL estimate results. To this end, the order of the lag distribution function should be selected using among the standard information criteria such as Akakie Information Criterion (AIC) and Schwaretz Bayesian Criterion (SBC).

The decision rule is that, if the computed F-statistics is higher than the appropriate upper bound of the critical value, the null hypothesis of no co-integration will be rejected. If it is below the appropriate lower bound, the null hypothesis cannot be rejected, and if it lies within the lower and upper bounds, the result would be inconclusive. As a sample size of this study is relatively small (38 observations), the study used the critical values reformulated by Narayan (2004) which was developed based on the sample size ranging from 30 and 80 observations rather than the reported value of Pesaran et al.(2001) which is appropriate for relatively a large sample size, for observations ranging from 500 and more.

Then, to check the verifiability of the estimated long run model, a number of diagnostic tests has been undertaken since it is required to check the standard property of the ARDL estimated ARDL model in Priority of doing any analysis through Serial correlation test (Brush \& Godfray LM test), Functional form (Ramsey's RESET) test, Normality (Jaque-Bera test), and Hetroskedasticity test. In order to reject or accept the null hypothesis, we can decide by looking the p-values associated with the test statistics. Specifically, the null hypothesis is rejected when the p-value are smaller than the standard significance level (that is ,5\%).

In addition to the above diagnostic tests, the stability of long run estimates has been also tested by applying the cumulative sum of recursive residuals (CUSUM) and the cumulative sum of squares of recursive residuals (CUSUMSQ) test as such tests are also recommended by Pesaran et al. (2001). The model faces a parameter instability problem if the CUSUM and or the CUSUMSQ plot(s) cross the lower and upper boundary of the plot at the given level of significance, and the model is dynamically stable otherwise.

After confirming the existence of long run relationship among the variables, the following stable long-run ARDL model can be estimated:

$\ln R G D P t=\alpha 0+\sum_{i=1}^{p} \alpha 1 \ln R G D P t-i+\sum_{i=1}^{p} \alpha 2 \ln P O P t-i+v t$.

Where $v t=$ is stochastic variable to accommodate the influence of other determinants of economic growth not included in the model in the long run and the remaining terms are as defined before.

3.2.3 Estimating the Error Correction Model (ECM) from the ARDL

Estimating a dynamic equation in the levels of the variables is problematic and differencing the variable is not a solution; so any information about the long run is removed. Therefore, the more suitable approach is to convert the dynamic model in to an error correction model (ECM).It shown that this contains information on both the short run and long run properties of the model, with disequilibrium as a process of adjustment to the long run (Harris, 1999).

The error correction (EC) representation of the ARDL model estimated previously can be expressed as: 


$$
\Delta \ln R G D P t=\alpha 0+\sum_{i=1}^{p} \alpha 1 \Delta \ln R G D P t-i+\sum_{i=1}^{p} \alpha 2 \Delta \ln P O P t-i+\theta 3 D+\delta E C M(-1)+u t \ldots .
$$

Where $E C M(-1)$ is error correction term lagged by one period. The error correction term (ECT) is derived from the corresponding long run model whose coefficients are obtained by normalizing the following equation:

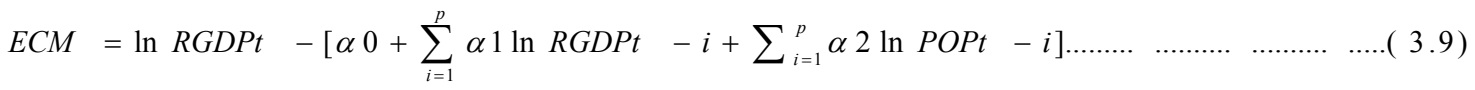

Where all terms are as defined before and the $\boldsymbol{\delta}$ is error correction parameters that measure the speed of adjustment towards the long run equilibrium within a year. In other words, the existence of an error-correction term among a number of co-integrated variables implies that changes in the dependent variable are a function of both the level of disequilibrium in co-integration relationship (represented by the ECM) and the changes in explanatory variables. Thus, the ECM tells one that any deviation from the long-run equilibrium will feed back on the changes in the dependent variable in order to force the movement towards the long-run equilibrium.

3.2.4 Granger Causality Test: The TYDL Approach

Causality test is important to determine whether one time series is useful in forecasting another or not (Enders, 1995) and following (Guajarati, 2004), there are four cases of causality:

i. Unidirectional causality from population growth to economic growth is indicated if the estimated coefficients on the lagged value of population growth are statistically different from zero as a group and the set of estimated coefficient on the lagged values of economic growth are not statistically different from zero as a group

ii. Conversely, unidirectional causality from economic growth to population growth exists if, the estimated coefficient of lagged value of economic growth is different from zero as a group and the set of the estimated coefficient of the lagged values of population growth are not different from zero as a group

iii. Feedback or Bilateral causality from population growth to economic growth and economic growth to population growth, when the set of coefficient of the lagged value of both variables are statistically significant in both regression equations.

iv. Independence, suggested when the set of lagged value of population growth and economic growth coefficients are not statistically significant in both regressions. Granger causality of population growth on economic growth or economic growth on population growth is absent, when lagged values of population growth or economic growth add no information on each other.

There are three approaches to implement the Granger causality test depending on time series properties; a Vector Autoregressive(VAR) model in the level series(VARL),a VAR model in the first differenced data(VARD), and a vector correction model(VECM).However, Phillips and Toda(1993,1994) argue that VAR estimation often involves nuisance parameters and then no satisfactory basis for mounting a statistical test of causality test applies as the F-test statistic does not have a standard distribution when variables are integrated. The VECM approach which involves pretesting through unit root and co-integration suffers from size distortions and thereby can often lead to mistaken conclusions about causality

Therefore, this study adopted the TYDL approach of Toda and Yamamoto(1995) and Dolado and Lutkepohu(1996).This approach has many advantages over the other methods of testing Granger non-causality. The TYDL approach is applicable irrespective of integration and co-integration properties of the model. The TYDL method better controls the type I error probability than other methods based on the VAR and VECM.

The basic idea behind the TYDL is to artificially augment the correct VAR order, $\mathrm{k}$, with $\mathrm{d}_{\max }$ extra lags, where $\mathrm{d}_{\max }$ is the maximum likely order of integration of the series in the VAR system. Thus, the following lag augmented VAR equation is specified for the population and RGD:

$$
\begin{aligned}
& \ln R G P t=\beta 10+\sum_{i=1}^{p} \theta 1 i \ln R G D P t-i+\sum_{i=p+1}^{p+d \max } \Omega 1 i \ln R D P t-i+\sum_{i=1}^{p} \delta 1 i \ln P o P t-i+ \\
& \sum_{i=p+1}^{p+d \max } \omega 1 i+u t \\
& \ln P o P t=\beta 20+\sum_{i=1}^{p} \theta 2 i \ln R G D P t-i+\sum_{i=p+1}^{p+d \max } \Omega 2 i \ln R D P t-i+\sum_{i=1}^{p} \delta 2 i \ln P o P t-i+ \\
& \sum_{i=p+1}^{p+d \max } \omega 2 i+v t
\end{aligned}
$$

From equation(3.10)\&(3.11), Casulity from $\ln P o p$ to $\ln R G D$ implies: $\delta 11=\delta 12=\ldots \delta 1 \mathrm{P} \neq 0 \&$ similarly, Causality from lnRGDP to lnPOP implies: $\theta 21=\theta 22=\ldots . .2 \mathrm{P} \neq 0$

Accordingly, Granger causality is tested using Modified Wald(MWald) test which is theoretically very simple, as it involves estimation of a VAR model augmented in straight ward way. 
3.2.5 Impulse Response Functions (IRFs) and Variance Decompositions

In empirical research, it is often necessary to know the response of one variable to an impulse in another variable in a system that involves a number of further variables as well. Thus, one would like to investigate the impulse response relationship between two variables in a higher dimensional system (Lutkepohi, 2005).To this end, generalized impulse response which is invariant to the ordering of the variables in the VAR has been used in this study.

An impulse response function traces the effect of a one standard deviation shock to one of the innovations on current and future values of the endogenous variables. A shock to the $\mathrm{i}^{\text {th }}$ variable directly affects the $\mathrm{i}^{\text {th }}$ variable, and is also transmitted to all of the endogenous variables through the dynamic structure of the VAR. The plots and impulse responses follow the distribution that summarize the results of the shock evaluation indicating the responses of each variable over the 10 years horizon to one standard deviation positive shock to each variable (Enders ,1995).

The results of VAR model estimated in equation (3.9) and equation (3.10) will not be interpreted like ordinary regression equations as they were not derived from structural equations as of (Enders ,1995). They were used for the generation of both the impulse response functions and for conducting the variance decomposition analysis, which will depict the effects of population growth on economic growth.

To infer the degree of exogeneity of the variables beyond the sample period, the decomposition of variance which measures the percentage of a variable's forecast error variance that occurs as a result of a shock from a variable in the system should be considered(Nayaran,2004).The orthogonalized forecast error variance decompositions are not invariant to the ordering of the variables in the VAR, the generalized forecast error variance decomposition which is invariant to the ordering of the variables in the VAR system is used in this study following.

\section{Estimation Results and Interpretations}

All the pre-estimation and post-estimation test results of the econometric models and the estimated results of the standard econometric models with respective interpretations and brief discussions are provided as bellows:

\subsection{The PP Unit Root Testing Result}

Table 4.1 Results for the PP Unit Root Test (Stata14 Output)

\begin{tabular}{|l|l|l|l|}
\hline $\begin{array}{l}\text { Variables (at level and first } \\
\text { Difference) }\end{array}$ & $\begin{array}{l}\text { t-statistics } \\
\text { (with drift only) }\end{array}$ & $\begin{array}{l}\text { t-statistics } \\
\text { (with drift and trend) }\end{array}$ & I[] \\
\hline $\ln$ GDP & 4.145 & 4.886 & \\
\hline$\Delta \ln R G D P$ & $-34.946 * * *$ & $-42.501 * * *$ & I[1] \\
\hline $\ln$ PoP & -42.490 & -38.914 & \\
\hline$\Delta \ln P$ PP & $-58.525 * * *$ & $-58 . e 659^{* * *}$ & $I[\mathbf{1}]$ \\
\hline
\end{tabular}

$* * *$ Sign indicates the rejection of the null hypothesis of non-stationary at $1 \%$ significance level and $\Delta$ denotes first difference, and the rejection of the null hypothesis is based on MacKinnon (1996) critical values

Source: Author's Own Computation

As it can be seen from Table 4.1, PP test witnessed that both variables are non-stationary at level under both specifications (that is, with constant only, and with constant and trend) since we cannot reject the null hypothesis of unit root .On the other hand, when the first difference of them are considered they become stationary at $1 \%$ level of significance under both specifications.

The PP test result above shows that the series are integrated with same order. That is, real GDP growth $(\ln R G D P)$, population growth $(\ln P o P)$ are both $I(1)$ or difference stationary variables. Thus, it is clear that none of the variable under the consideration are I(2).Therefore, the PP test result implies that the ARDL co-integration testing technique proposed by Pesaran et al.(2001) is the most appropriate method to be adopted in the study. 
4.2 Coefficients and Residual Diagnostic Testing Results

Table 4.2 Coefficients and Residual Diagnostics Test Results

\begin{tabular}{|l|l|}
\hline \multicolumn{1}{|c|}{ Test } & F-Version Test-Statistics[Probability] \\
\hline A: Serial Correlation & Fcal $=0.973243[0.4864]$ \\
\hline B: Functional Form & Fcal $=2.275173[0.1657]$ \\
\hline C: Normality & Jarque-Berra $=1.643978[0.439557]$ \\
\hline D: Heteroskedasticity & Fcal $=0.559880[0.8766]$ \\
\hline R -Squared $=0.998 \quad$ Adjusted R-Squared $=0.997$ \\
DW $=2.23$ \\
A: Lagrange multiplier test of residual serial correlation \\
B: Ramsey's RESET test using the square of the fitted values \\
C: Based on a Histogram test of Skewness and kurtosis of residuals \\
D: Based on the regression of squared residuals on squared fitted values \\
\hline
\end{tabular}

Source: Author's Own Computation

A. The Brush Godfray LM test failed to reject the null hypothesis of no serial correlation for the reason that that the p-values associated with test statistic is greater than the standard significant level (that is, $0.973243>0.05)$.

B. Since 0.1657 exceeds 0.05 , the Ramsey's RESET test can not reject the null hypothesis of the functional form of the model which says that the model is correctly specified. In other words, We cannot reject the null hypothesis for Ramsey's RESET test, which tests whether the model suffers from omitted variable bias or not. The test result indicates that the model is correctly specified.

C. The third diagnostic test is about the residual. As the result indicates, we cannot reject the null hypothesis which says that the residuals are normally distributed since the p-value associated with the Jarque-Berra normality test is larger than the standard significance level (that is, 0.439557 is greater than 0.05).This indicate that the residual is normally distributed as assumed prior.

D. The last diagnostic test is for heteroskedasticity. As we can see from Table 4.3, we cannot reject the null hypothesis of homoskedasticity at $5 \%$ significance level as p-value associated with the test statistics is greater than the standard significance level( that is, 0.8766 is greater than 0.05).This implies that the residual possess time in-variant or constant variance. Combining this with the normality test result we can conclude that the residual is white noise.

In general, Table 4.4 indicates that the selected ARDL $(1,1)$ which is estimated in this study passes all the diagnostic tests implying that the long run and short run coefficients are efficient and reliable. 


\subsection{Testing Results of Model (Parameter) Stability Using CUSUM and CUSUMSQ Tests}

\section{A. Plot of Cumulative Sum of Recursive Residuals}

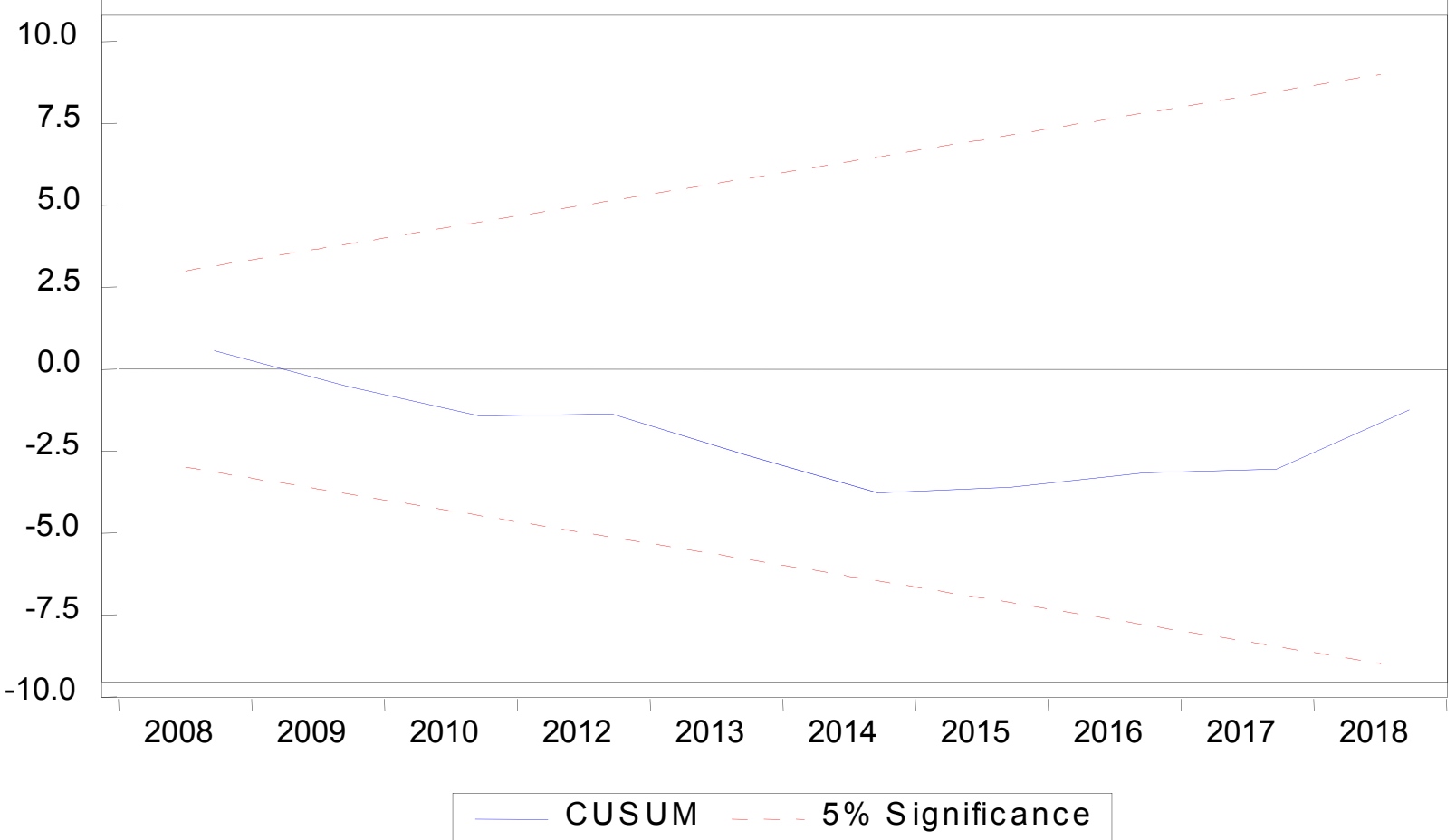

\section{B. Plot of Cumulative Sum of Squares of Recursive Residuals}

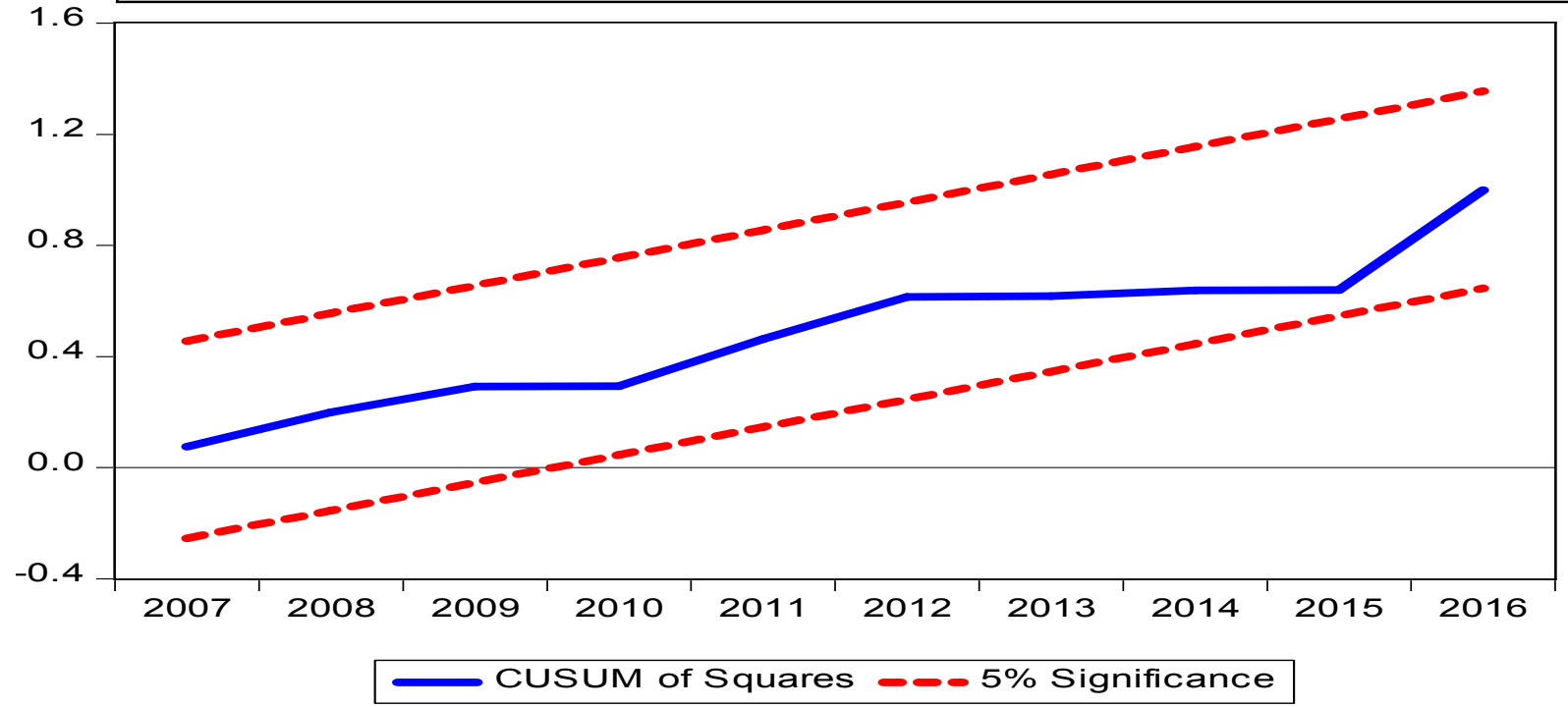

Figure 4.1: Plot of Cumulative Sum of Recursive Residuals (CUSUM) and Cumulative Sum of Squares of Recursive Residuals (CUSUMSQ)

As it can be seen from the first figure, the plot of CUSUM test does not cross the critical limits. Similarly, the CUSUMSQ test shows that the graph does not cross the lower and upper critical limits. So, it is possible to conclude that long run estimates are stable and there is no any structural break in parameters. 
4.4 Bound Testing Result of the Estimated ARDL Model

Table 4.4 Bounds Test Result (Eviews10 Output)

\begin{tabular}{|l|l|}
\hline \multicolumn{1}{|c|}{ Description } & \multicolumn{1}{c|}{ Value } \\
\hline Number of Observation & 37 after adjustment for lag \\
\hline Calculated F-Statistics & 8.269899 \\
\hline
\end{tabular}

Source: Author's Own Computation

Table 4.5 critical values for bound test: Case III restricted intercept and Trend

\begin{tabular}{|l|l|l|}
\hline \multirow{2}{*}{ significance level } & Narayan (2004) CV, k=2 \\
\cline { 2 - 3 } & Lower Bound (I(0)) & Upper bound (I(1)) \\
\hline 1 percent & 2.753 & 5.669 \\
\hline 5 Percent & 2.750 & 4.211 \\
\hline 10 Percent & 2.306 & 3.588 \\
\hline
\end{tabular}

Source: Narayan (2004) critical values

The Narayan(2004) critical values reported on Table 4.5 above were that formulated for the case of ARDL estimated with unrestricted intercept and no trend (that is, case III). Moreover, the Narayan(2004) critical values are the reformulated values for 30 to 80 observations unlike the Pesaran et al.(2001) values which were formulated based on 500 to 1000 observations.

Table 4.6 shows that $\operatorname{lnRGDP}$ and $\ln P o P$ are co-integrated since the F-statistic, also written as $\mathrm{F}_{\operatorname{lnRGDP}}$ (lnRGDP $\mid \ln$ PoP) equals to 8.299899 for the estimated ARDL model with optimum lag order ARDL $(1,1)$ and specified with an intercept and trend is higher than the Narayan (2004) upper bound critical values at 1 percent level of significance.

This implies that the null hypothesis of no long-run relationship (that is, $\mathrm{H} 0: \Theta 0=\Theta 1=\Theta 2=\Theta 3=0$ ) is rejected and the alternative hypothesis of long-run relationship (that is, $\mathrm{H} 1: \Theta 0 \neq \Theta 1 \neq \Theta 2 \neq \Theta 3 \neq 0$ ) is accepted through bound test.

4.6 Long Run ARDL Model Estimation Result

Table 4.6 Estimated Long Run Coefficients ARDL(1,1)

\begin{tabular}{|l|l|l|l|l|}
\hline \multicolumn{5}{|c|}{ Dependent variable is InGDP } \\
\hline Regressor & Coefficient & Std. Error & t-Statistic & Probability \\
\hline LnPoP & $1.1294411^{* * *}$ & 0.061876 & 18.25282 & 0.0000 \\
\hline $\mathrm{EC}=\ln$ RDP-(1.12944111nPoP) \\
*** sign denote the significance of the coefficient at 1\%
\end{tabular}

Source: Author's Own Computation

Table 4.6 indicates that the long run coefficient of population growth (lnPoP) is 1.1294411 and it is statistically significant at 1 percent. Therefore, at citrus paribus, one percent increase in Ethiopian population will lead to 1.1294411 percent, that is, more proportionate increase on economic growth, on average.

The result is in-line with the optimist theory of Population.More specifically, the result is consistent with the arguments' of optimistic viewers such as Boserup, Simon Gray and Mercantilists who believed that population growth induces economic growth; by providing the needed consumer demand to generate favorable economies of scale in production to lower production costs, by providing a sufficient and low cost labor supply and thereby reducing cost of production and discouraging the idleness that might become associated with higher wage levels, by putting more pressure on the existing agricultural system and thereby encouraging invention of new technologies and bringing institutional changes.

Moreover, the result is consistent with the findings of Kassahun (2014) for the case of Ethiopia, Gideon et al.(2013) for case of Kenya, Nwosu et al.(2014) and Emmanul(unpublished) for the case of Nigeria .

\subsection{Error Correction Model (ECM) Estimation Result}

As it can be referred from the table below, the error correction coefficient is estimated at negative 0.931244 and it is statistically significant at one percent significance level, and imply a very high speed of adjustment to equilibrium. The minus 0.931244 value implies that about 93.1277 percent of any movements into disequilibrium are corrected (adjusted) within one period, and thus, the total adjustment will take a year and about a month. Said in another way, the coefficient of the error term implies that the deviation from long run equilibrium level of real GDP in the current period is corrected by 93.1277 percent in the next period and it is highly significant. 
Table 4.7 Error Correction Representation of the estimated ARDL (1,1) selected based on AIC.

\begin{tabular}{|l|l|l|l|l|}
\hline \multicolumn{5}{|l|}{ Depedent Variable: $\ln R$ GDP } \\
\hline Regressors & Coefficient & Stand. Error & t-Statistic & Probability \\
\hline Constant & $-25.85358 * * *$ & 2.987537 & -8.653809 & 0.0000 \\
\hline Trend & $-0.048970 * * *$ & 0.006128 & -7.991503 & 0.0000 \\
\hline$\Delta \operatorname{lnPoP}$ & $0.549645 * * *$ & 0.2211531 & 2.598417 & 0.0003 \\
\hline$\Delta \operatorname{lnPoP}(-1)$ & -0.373298 & 0.251090 & -1.486711 & 0.0266 \\
\hline Policy Dummy(PD) & $-0.044092 * * *$ & 0.005829 & -7.563744 & 0.0000 \\
\hline ECM(-1) & $-0.931244 * * *$ & 0.107942 & -86.27230 & 0.0000 \\
\hline $\begin{array}{l}\text { R-squared: } 0.995885 \\
\text { Adjusted R-Squared: } 0.991253\end{array}$ & F-Statistics : 23.5909[0.000000] \\
\hline
\end{tabular}

*** Sign denotes the significance of the coefficients at 1\% significance level

Source: Author's Own Computation

According to Bannerjee et al.(2003) as cited in (Kidanemarim ,2014), the highly significant error correction term further confirms the existence of a stable long-run relationship.

The coefficient of determination (R-squared) which measure the "goodness of fit" of the model is very high (that is, 0.99). It indicates that $99 \%$ of variations in Ethiopian economic growth are explained by the variations in Ethiopian population growth and the policy reforms. Thus, only about one percent variation in real GDP is left unexplained which in turn has been already captured by the error term. In addition, the DW- statistic does not suggest autocorrelation and the F-statistic is quite robust implying that all the repressors are jointly significant to explain economic growth.

When the short run impact of population on economic growth is interpreted; other things remaining constant, a percentage increase in Ethiopian population will increase real GDP by 0.55 percentages, on average. This implies that population growth has significant positive impact on economic growth of Ethiopia both in long run and short run. This is in-line with prior expectation and is also consistent with the existing wisdom.

The coefficient of policy dummy support that the level of economic growth achieved during the EPRDF regime(1991-present) is higher than that of the level of economic growth attained during the Dergue regime(19741991 ) in the country. Specifically, when we compare the level of economic growth between the two successive regimes; all other things being equal, the level of economic growth achieved during the Dergue period is less than the level achieved during the existing regime by 0.931244 units, on average. Moreover, the historical evidence of economic performance indicators including the real GDP growth itself supports the result as Ethiopia has made enormous policy reforms since the EPRDF regime overtook power, and thereby the country has been recording double digit economic growth and running one of the biggest economies in Sub-Saharan Africa.

\subsection{The TDYL Causality Testing Result}

Table 4.8 VAR Lag Order Selection Criteria

\begin{tabular}{|l|l|l|r|}
\hline Lag & LogL & LR & FPE \\
AIC & SC & HQ & 0.007871 \\
\hline 0 & -4.322413 & NA & 0.351245 \\
\hline 1 & 0.434918 & 0.381950 & $-9.548258^{*}$ \\
& 179.5267 & $337.0567^{*}$ & $-9.640373^{*}$ \\
\hline
\end{tabular}

*indicates lag order selected by the criterion, LR is sequential modified LR test statistics (each test a 5\% level), FPE is final prediction error, AIC is Akaike Information Criterion, SC is Schewarez Information Criterion and HQ is Hannan-Quinn information criterion.

Source: Author's Own Computation

As it can be seen from Table 4.9, the optimal lag length is one. And since the variables become stationary after first differencing as suggested by PP test, it implies that $\mathrm{d}_{\max }$ is also one. Therefore, the researcher estimated a system of VAR in levels with a total of $\left(\mathrm{d}_{\max +\mathrm{k}}=1+1\right)$ which is 2 lags where $\mathrm{k}$ is the lag length selected by information criteria. Using this information, the system of equations (that is, equation 3.10 and 3.11 ) is jointly estimated.

And then, following the TYDL approach, the augmented VAR of order two is estimated and the Wald test is performed only on the coefficients of first lag. 
Table 4.9 Estimates of Long Run Granger Causality based on TYDL Approach (Eviews10 Output)

\begin{tabular}{|l|l|l|l|}
\hline Null Hypothesis & Chi-sq $\left(\boldsymbol{X}^{\mathbf{2}}\right)$ & Prob. & Decision \\
\hline lnPOP does not Granger Cause lnRGDP & $6.079209^{* *}$ & 0.4144 & Reject Ho \\
\hline LnRGDP does not Granger Cause lnPOP & $12.52947^{*}$ & 0.0511 & Reject Ho \\
\hline
\end{tabular}

**and* indicates the significance at $5 \%$ and $10 \%$, respectively

Source: Author's Own Computation

From the output of TYDL Granger Causality test reported in table 4.10 above, the results suggested that there is bi-directional causality running from economic growth to population and from population growth to economic growth. The result is supports the finding of Gideon et al. (2013) and it may also support the result of Becker (1981) who found out that when a country is in a demographic transition, population growth increases with an increase in economic growth in the short run, thereby would suggest that Ethiopia in demographic transition.

Considering the causality from economic growth to population growth first, it is likely that in the short term, high economic growth in a developing country will increase population growth, mainly through reducing mortality rates. This is the typical process of a country beginning a demographic transition which initially increases population growth rates. In the long term, however, it is very likely that economic growth will reduce population growth as wealthier parents choose smaller families which will over time reduce population growth as in the case of rich countries.

On the other hand, the causality from population growth to economic growth could be attributed to due to increased expenditure of government on different programs and on the increased demand for basic infrastructure services.

Table 4.10a Generalized Impulse response one Standard Error (SE) Economic Growth

\begin{tabular}{|l|c|c|}
\hline Period & lnRGDP & $\ln$ PoP \\
\hline 1 & 0.043966 & 0.014070 \\
2 & 0.044244 & 0.015760 \\
3 & 0.022088 & 0.018269 \\
4 & 0.012445 & 0.028721 \\
5 & 0.021041 & 0.031556 \\
6 & 0.013556 & 0.033022 \\
7 & 0.017173 & 0.038128 \\
8 & 0.026683 & 0.041221 \\
9 & 0.025376 & 0.047304 \\
10 & 0.021077 & 0.052300 \\
\hline
\end{tabular}

Source: Author's Own Computation

(a).The impact of Economic growth on population growth.

Table 4.10a illustrates the estimated generalized impulse response functions of variables population growth (lnRGDP) for ten years. A one standard deviation disturbance originating from economic growth results in an approximately 1.4 percent increase in population in the first period and then it continuously increases 3.1 percent in 5 th period and finally reaches 5.2 percent in the tenth period. This shows that the impact of economic growth on population growth is permanent. This result is in support of Becker (1981) who found out that when a country is in a demographic transition, population growth increases with an increase in economic growth in the short run.

Table 4.10b Generalized Impulse response one SE for Population Growth

\begin{tabular}{|l|r|r|}
\hline Period & $\ln$ GDP & $\ln P$ PP \\
\hline 1 & 0.023966 & 0.041407 \\
2 & 0.034244 & 0.04276 \\
3 & 0.036208 & 0.488269 \\
4 & 0.037244 & 0.051872 \\
5 & 0.041041 & 0.05560 \\
6 & 0.041355 & 0.0566302 \\
7 & 0.042717 & 0.056642 \\
8 & 0.052668 & 0.0567211 \\
9 & 0.056537 & 0.0568040 \\
10 & 0.057207 & 0.0473000 \\
\hline
\end{tabular}

Source: Author's Own Computation

(b). The impact of population growth on economic growth

Table $4.10 \mathrm{~b}$ illustrates the estimated generalized impulse response functions of variables population growth $(\ln P o P)$ for ten years. A one standard deviation disturbance originating from population growth results in an approximately 2.3 percent increase in economic growth in the first year, by 4.1 percent in the next period and reaches 5.7 percent in the tenth period by growing continuously. This indicates that the impact of population on economic growth is 
does not die out with the increase in time horizon.

4.11 Variance Decompositions Analysis Results

Table 4.11a Generalized forecast error variance for economic growth (InRGDP):Eviews10 Output

\begin{tabular}{|l|c|c|}
\hline Horizon & lnRGDP & $\operatorname{lnPOP}$ \\
\hline 1 & 100.000 & 0.000000 \\
2 & 94.75217 & 5.247835 \\
3 & 89.30721 & 10.69279 \\
4 & 86.59165 & 13.40835 \\
5 & 80.53165 & 19.46835 \\
6 & 73.88199 & 26.111801 \\
7 & 71.27054 & 29.48604 \\
8 & 70.51396 & 29.48604 \\
9 & 68.59155 & 31.40845 \\
10 & 66.69597 & 33.403 \\
\hline
\end{tabular}

From Table4.11a,the results of Variance Decomposition analysis of economic growth rate show that all the variations in economic growth rate were due to its own shocks at 100 percent in the first year implying that population growth did not contribute at all to the variations in economic growth in the first year. The variations of own shocks in economic growth reduced to 94.75 percent in the second year. In the third year the variations further reduced to 89.3 percent and continued to reduce as the forecasting horizon increased. The forecast error decomposition technique continues to reveal that after the first year, the variations in economic growth are dependent on its own composition and variations in population growth.

Table 4.11b Generalized forecast error variance for Population Growth (InPOP)

\begin{tabular}{|l|c|c|}
\hline Horizon & $\operatorname{lnRGDP}$ & $\ln$ POP \\
\hline 1 & 0.102390 & 99.89761 \\
2 & 10.67457 & 89.32543 \\
3 & 13.49168 & 86.50832 \\
4 & 11.27737 & 88.72630 \\
5 & 9.155611 & 90.84439 \\
6 & 7.541822 & 92.45818 \\
7 & 6.819846 & 93.18015 \\
8 & 5.843586 & 94.15641 \\
9 & 5.787776 & 94.21222 \\
10 & 5.8222434 & 94.17757 \\
\hline
\end{tabular}

Source: Author's Own Computation

Table $4.11 \mathrm{~b}$ presents the generalized forecast error variance decomposition for population growth ( InRGDP).The result also revealed that the effect of population growth in the system increased with the increase in forecast period. This implies that economic growth has feedback effects with population growth and the effects are multidirectional. This collaborates with the TYDL causality test result which witnessed the existence of bidirectional causality between population growth and economic growth.

\section{Conclusions}

The study examined the impact population growth on economic growth in Ethiopia for the period 1980/81-2016/18 using a recent and popular methodology of ARDL Bounds Testing.It study also indentified the direction of dynamic causality between population growth and economic growth using TYDL approach. And the results under both approaches are found robust.

The empirical result revealed that population growth has significant positive relationship with economic growth both in the short run and long run. More specially, at citrus paribus, one percent increase in Ethiopian population will lead to 1.1294411 percent (that is, more than proportionate) increase on economic growth in the long run. Again, all other things being equal, one percentage increase in Ethiopian population will increase its real GDP by 0.55 percentages, on average, in the short run. The results of impulse response function supported these results by showing that impact of population on economic growth is permanent. Moreover, the results of YTDL causality testing approach suggest that there appears to be bi-directional causality when causality is assumed to run from population to economic growth or from economic growth to population growth. Overall, the relationship between population and economic growth is strong and positive in Ethiopia over the periods of the study.

The findings give support to the population-driven economic growth hypothesis that states the population growth in a country's promotes its economic growth and development. The findings also suggests that Ethiopia seems to be in the second stage of the demographic transition, called post Malthusian regime, in which the 
relationship between economic growth and population growth remains strong and positive

\section{Policy Implications}

A carefully planned population growth strategy coupled with efficient and effective institutional and economic policy changes could be beneficial. A well managed population expansion will ensure that both the population and the economy are complementing each other without concerns that population expansion will lead countries to famines and lack of other socio economic facilities since it's the inadequate and ineffective government policies, rather than population growth which are responsible for the woes including, famines that devastate most developing nations.

The government should also put measures to sustain the existing economic growth which has been growing at a higher rate than the population growth. This will ensure that the increasing demand of goods and services arising from the population growth is met. Having a larger, healthier, and better-educated workforce will only bear economic fruit if the extra workers can find jobs. As a result, open economies, flexible labour forces, and modern institutions that can gain the confidence of the population and markets alike may help country reap the potential benefit created by its demographic transition.

The purpose of sustainable development is to create and improve an environment in which all people can expand their capabilities and requires good governance. That concept is distinguished by its transparency and accountability as well as its effectiveness and justice in social, economic and political spheres. The provision of employment opportunities is the peak of any economic and social reform plan that aims to improve quality of life by achieving sustainable human development. In that respect, the role of good governance in providing job opportunities need to be emphasized. A better political environment would also encourage private investment since its contribution to economic growth cannot be under estimated. And the impact of the other dimensions population such as population density, size, structure and population aging on economic growth requires in-depth investigations.

\section{References}

Anonymous(2014),"world countries per capita income report, The journal of political Economy, Vol.98, (5):103125.

Bloom D. E. \& Freeman R. (1999),“The Effects of Rapid Population Growth on Labour Supply and Employment in Developing Countries". Population and Development Review,381-414.

Boserup E. (1965), "The Conditions of Agricultural Growth: The Economics of Agrarian Change under Population Pressure", London

CIA WFB(2014).Overview of African Population

CSA(2007); Reports of the 1994, 2006 and 2007 population and housing census and 2012 inter-censual survey.

Dawit,T. (2013), "The impact of public capital spending on economic growth in Ethiopia" Economics, Bahir Dar University. Msc Thesis.

Enders W.(1996), “Applied Econometric Time Series” Lowa State University: John Wiley \& Sons INC.

Gideon K.T, Gachanja P. and Obere A.(2013), "The Impact of Population Change on Economic Growth in Kenya".Kenyatta University P.O. Box 43844 Nairobi, Kenya

Granger, C.W.J(1969), "Investigating causal relation by econometric and cross-sectional method. Econometrica, 37: 424-438.

Gujarati, D. (2004) .Basic Econometrics, Fourth Edition, the McGraw-Hill Companies

Harris R.(1999), "Using Co-integration Analysis in Econometric Modeling".London, prentice hall.

Hutchinson, E. (1967): The Population Debate, Houghon Mifflin Company, Boston

Jhagan (2002), "The Economics of Development and Planning", New Delhi, India

Kassahun A.(2014), "Impact of Population Growth on the Ethiopian Economic Performance", A Project Submitted to the School of Graduate Studies of Addis Ababa University, Addis Ababa, Ethiopia

Lutkepohi H.(2005).New Introduction to Multiple Time Series Analysis.Berlin:Springer

Malthus T.R.(1798), "An Essay on the Principles of Population", Cambridge University Press.

Martin P.(2009) "Demographic and Economic Trends: Implications for International Mobility" United Nations Development Program Human Development Reports. Research Paper 2009/17

Narayan P.K.(2004).Reformulating Critical Values for the Bounds F-stastics Approach to Cointegration.An Application to the Tourism Demand Model for Fiji.Department of Economics Discusion Paper 02/04.Monash University.Melbourne,1-32.

Nwosu C., Dike A. \& Okwara K..(2014), “The Effects of Population Growth on Economic Growth in Nigeria"

Obere A. ,Gideon K.T. \& Gachanja P.(2013) "The Impact of Population Change on Economic Growth "IJEMS. (2), 43-60.

Pesaran M.H,Shin Y.,Smith R.J.(2001).Bounds Testing Approaches to the Analysis of Levels Relationships.J.Appl.Econom.,16:289-326. 
Pesaran M.H., Shin Y.\& Smith R.J (2001), "Bound Testing Approach to the Analysis of Level Relationships", Journal of Applied econometrics, 16:289-326

Pesaran MH.\&Shin Y.(1999), “An Autoregressive Distributed Lag Modeling Approach to Co integration Analysis" in S. Strom, Econometrics and Economic Theory in the 20th Century

Philips P.C \& Toda H.Y(1994).Vector Autoregression and Causality: A Theoritical Overview and Simulation Study.Econometric Review,13(2):259-285

Philips P.C,\&Toda H.Y.(1993).Vector Autoregression and Causality.Econometrica,61(6):1367-1393

Rostow W.W., (1998) “Historical Stages of Economic Development”,New York Oxford University Press.

Simon J. L. (1977), "The Economics of Population Growth" ,Princeton University Press, Princeton New Jersey. Simon J.L.(1992) ,"Population and Developing Countries", Princeton University Press .Princeton, New Jersey.

Smith A. (1776). "An Inquiry into the Nature and Causes of the Wealth of Nations", first Published in 1776, The Glasgow Edition of the Works and Correspondence of Smith, A. two voles, Oxford University Press.

Todaro M.P.\& Smith S.C.(2003), "Economic Development", Business \& Economics ,829; Addison Wesley

Verbeek M. (2004):A Guide to Modern Econometrics(2 ${ }^{\text {nd }}$ ed.),Erasmus University Rotterdam. 